\title{
Designing for Musical Play
}

\author{
Ben Challis \\ Department of Contemporary Arts, Manchester Metropolitan University, \\ Cheshire Campus, Crewe Green Road, Crewe, Cheshire, CW1 5DU, UK. \\ B.Challis@mmu.ac.uk
}

\begin{abstract}
Though sensory spaces are a common feature within many special needs schools, the way in which they are designed and resourced varies greatly between provisions as do the types of activities that take place within them. A short series of case studies has been carried across a cross section of UK special needs schools to demonstrate this contrast whilst also attempting to better understand the reasoning and motivation behind their design and usage. In 2012, eight schools were visited in England and Wales with the aim of documenting the types of sensory space that were available, the resources that were featured within each space and the types of sensory activities that were being used. The key themes that emerged during the case studies are discussed alongside an historical overview of the conception and evolution of the multisensory environment.
\end{abstract}

Keywords: sensory, play, sound, music

\section{Introduction}

This chapter aims to explore the use of music and sound through assistive improvised-play in sensory spaces. The term 'assistive' is used here by way of reference to any technology (specialist, commercial, novel) that is in some way enabling within a context of creating and manipulating sonic-landscapes or musical-ideas. Whilst acknowledging that there are clear benefits to encouraging children and adults with perhaps quite profound individual-needs to engage with sensory focused activities, it is also suggested that there is a need for a more coherent approach to designing such spaces. A recent series of visits to special needs education (SNE) schools has shown there to be a wide spectrum of perceptions on offer as to the kinds of activities that might take place in sensory spaces and that this, in turn, is reflected in the considerable variety of layouts and technologies that can be observed in use. This spectrum ranges from the ad-hoc (or perhaps organic) approach to design through to commercially commissioned spaces with feature-rich content. A broad range of sensory stimuli and technologies exist within this spectrum, offering contrasting levels of emphasis across the types and nature of interactions being explored (tactile, haptic, auditory, visual). In addition, there are certain technologies (e.g. the bubble-tube) that can be regarded as common features and others (e.g. the resonance board) 
that are not and there are good examples of 'found' technologies that perhaps surpass the potential offered by many specialist technologies.

Sensory spaces can perhaps now be regarded as ubiquitous within SNE provision with designs for new buildings and extensions identifying areas for use as a sensory room or sensory garden and with existing provision identifying available space to be offered over for such use. However, there is little literature available on either the design of sensory spaces or how to get the most out of their potential when they are available. So this raises the fundamental question as to what different combinations of layout, technologies and activities can be regarded as 'good'? There is unlikely to be an absolute answer to this question and the very nature of individual needs dictates that different provisions are likely to have different solutions based on the specific therapeutic requirements of the individuals they are working with. However, there is much to share here and this chapter attempts to detail some of this within a discussion that is nonjudgemental; the aim being to elaborate on contrasting approaches with a view to helping practitioners make informed design choices that suit their own needs. Within this, there will be significant emphasis placed on the notion of interaction through improvised-play. The suggestion being that, although cause and effect style interactions are of obvious benefit (the bubble tube being a good example of this), there could be more opportunities for free-play within sensory spaces; where outcomes are perhaps less deterministic whilst still being mapped in a meaningful way to an individual's gestures.

Alongside this key theme of design for 'play', the chapter will also propose that interaction with music and sound in sensory spaces is perhaps underexplored. A key observation within the survey is that music and sound are often employed in a passive sense within sensory spaces; providing an ambient backdrop to other sensory activities for example. Even when the interaction is more active, the use of sound and music can often be restricted to a cause-and-effect style approach. For example, a sensory garden may contain an ornamental flower that when hit or touched produces an appropriate sound (e.g. the buzz of a bee); the single action is rewarded with a single sound. In contrast, it is a rarity to find examples where the subtleties of more prolonged movement (moving a hand or body within a field or across a surface) are captured and mapped to meaningful sonic events. These two key themes (design for play and interactivity for music and sound) will be maintained throughout the following observations and discussions.

\section{Snoezelen and the evolution of the sensory space}

Schools for special needs education will often have one or more areas that can be identified as being a sensory space ${ }^{1}$, yet there is little consensus on how such a space might be designed, resourced and, ultimately, used. There are commercial companies that will design and equip such spaces, offering a range of specialist technologies and furnishings along the way yet there is little research available

\footnotetext{
${ }^{1}$ Sensory spaces are also referred to as multisensory environments or MSEs.
} 
to suggest why one combination of resources might be more effective than another. So, where does the concept of the sensory space come from and what transformations have occurred throughout its evolution?

The original concept behind the sensory space can be attributed to the work of Hulsegge and Verheul [1] who suggested that fundamental sensory stimulation could be a more direct and meaningful way of reaching out to individuals with profound and multiple learning difficulties (PMLD) than that of focusing on intellectual ability alone. In their book 'Snoezelen: Another World', Hulsegge and Verheul describe the creation and use of sensory rooms for this purpose at the De Hartenberg Centre in the Netherlands. The rooms were essentially controlled sensory environments where a care-assistant could work alongside an individual with PMLD as he or she interacted with various sensory stimuli. Importantly, the emphasis was not on learning in any traditional sense, more on recreation and play with contrasting sensory experiences readily on hand for the individual to explore. Indeed the term 'Snoezelen' is derived from two Dutch words: 'snuffelen' to sniff and 'doezelen' to doze and though learning might be achieved within these sessions it was not regarded as a primary aim.

Pagliano [2] describes how these multisensory environments were, in part, born from the coming together of specific technological and social changes. The late 1970s saw the emergence of the discotheque, a high-tech environment dedicated to the creation of powerful audio-visual experiences for the purpose of entertainment alone. New technologies were being developed to enhance these sensory experiences (mirror-balls, sound-to-light, projector-wheels), all against a backdrop of amplified beat-based music. At this same time, the manufacturing industry was exploring the potential for various new plastic technologies. Softplay furnishings could now be produced easily using PVC; not only cheap to manufacture but waterproof and easy to wipe-clean. Velcro was being used to produce simple but effective instant-access fasteners and vacuum-formed plastics were enabling the creation of lightweight playground equipment. The arrival of these technological novelties (discotheque and versatile plastics) happened to coincide with a number of sociological changes that were evolving in the way in which individuals with disabilities were being perceived and supported; a progressive movement away from institutionalisation and towards mainstream integration. The Snoezelen effectively embodied all three of these notable happenings, creating safe environments where individuals with PMLD could experience rich sensory experiences in a recreational and, ultimately, therapeutic context.

The Snoezelen model was adopted relatively rapidly within special needs and on quite a global scale leading, in turn, to the rapid commercialisation behind the manufacture of many associated technologies. Ultimately, Snoezelen became the registered trademark of one specific company and though this remains to be the case there are numerous other companies (in design, consultancy and manufacturing) that very much owe their existence to this original concept. There are various names and permutations that are now in use and besides the registered trademark of Snoezelen, any special needs school might describe how it has one or more multisensory environments, though the term used might be 
sensory room, a sensory garden, maybe a sensory corridor or even a sensory corner. Portable sensory trolleys exist too such that a dedicated room or area is not required and activity rooms (hydrotherapy pools, rebound rooms etc.) might be enhanced to also function as some form of sensory environment. With this in mind, the term sensory space is being used within this chapter as a catch-all term for any such realisation or adaptation of the original Snoezelen concept.

Though the design and installation of sensory spaces continued steadily, the underlying philosophy was often confused, leading to mixed interpretations and experiences along the way. Indeed, the originators of the Snoezelen concept acknowledged this in their own writings identifying a general lack of solid theoretical basis from which to understand and guide Snoezelen use. Pagliano $[2,3]$ highlights this further by describing specific contradictory examples such as the suggestion by Hulsegge and Verheul that expertise is not absolutely necessary even though they also emphasised the need for careful observation and, more significantly, that learning is not a must even though the individuals should be given the opportunity to gain experience. Ultimately this lack of clarity led to the branching of the original concept into two separate ideologies, one that stayed true to the original philosophy where the emphasis would be placed on recreation only and one that moved more towards an educational model where emphasis would be placed on learning through cause and effect. In a study into the perception and purpose of sensory spaces, Bozic [4] formalises these two contrasting approaches as being part of either a child-led repertoire or a developmental repertoire. He also points out that both repertoires may well coexist within the same school as it is generally individual members of staff who are ultimately responsible for interpreting the function and use of sensory spaces.

Though sensory spaces can be regarded as widely available within SNE provision in the UK, there is very little research available that questions whether there are measurable benefits from using such resources. Where research has been carried out the results have tended to be inconclusive (e.g. $[5,6])$ or perhaps not open to generalisation (e.g. [7]). Indeed, in a review of available research in this area Hogg et al [8] also identify examples of negative outcomes commenting that

"Snoezelen is not a cure-all for everyone - even those with apparently similar characteristics ..."

suggesting that

"... efforts must be made to establish what the individual brings to the situation in terms of personality and sensitivities that makes Snoezelen beneficial, a non-event, or positively detrimental".

Whilst a more recent meta-study by Lotan and Gold [9] concluded that

" ... weaknesses in the examined research methodologies, the heterogeneity between research designs, the small number of available research projects, and the small number of participants in each research project, prevent a confirmation of this method as a valid therapeutic intervention at this time." 
So, the long-term benefits of working with sensory spaces are yet to be fully assessed and this places considerable reliance on anecdotal evidence for identifying any potential positive or negative impact. There is still substantial value to be attached to personal observations and experiences though, as the special needs educator is typically working at an individual needs level where the opportunity to generalise rarely arises anyway. This is an aspect that Mount and Cavet [10] identify in their review of similar studies into the relative merits of sensory spaces, ultimately arguing that there is likely to be as much significance to be placed on the quality and abilities of the individual member of staff as the equipment and spaces they are operating within.

The Snoezelen philosophy identified music and sound as being an important part of the sensory environment but was not prescriptive as to how this might be achieved. In many of the sensory spaces visited for this study, interaction with music was typically a passive activity yet music is also used in very active ways within other therapeutic contexts. Though more active interaction with sound and music did occur elsewhere within the schools visited it was seldom observed directly within the sensory spaces where one-to-one sessions might be more likely to occur. This observation is discussed in greater depth later on but as the emphasis of this chapter is on musical-play within sensory spaces the following section outlines a few key points in connection with the therapeutic potential of music and improvised play.

\section{Music and sound in therapeutic contexts}

For many people, the idea of engaging in music-making activities may well also suggest a need to adhere to formal structure; harmonic progressions, rhythmic patterns, melodic phrases and so on. However, music can also operate at a much more abstract level where there are less formal rules to follow. Free jazz, for example, explores this notion whilst retaining some of the sounds and textures that perhaps instil the 'feel' of jazz. At a more fundamental level, free improvisation offers a considerable sense of freedom. However, the absence of agreed structure in improvised music does not negate the emergence of shared ideas, or the development and reiteration of phrases and patterns, nor does it exclude the exploration of tonality, meter and harmony. Perhaps more liberating is the notion that such formal musical constructs do not have to be predefined or even visited at all for music to happen. In essence, free improvisation encourages us all to play with sound, to offer new ideas and perhaps reflect those we hear around us, to embrace or resist the musical flow and to develop or simply abandon a train of musical thought.

This same concept of musical play is fundamental to key applications of music in therapeutic settings. Musical play exists in a clinical setting where a Music Therapist will use improvised music as a tool for creating a relationship with a client for therapeutic purposes; it also exists in Community Music where groupbased musical activities can have therapeutic outcomes. Both Music Therapy 
and Community Music can employ game-like strategies for creating, sharing and generally communicating musically.

Clear definitions for both Music Therapy (and Community Music) are understandably difficult to create given their potential breadth and reach but the following is a meaningful working definition.

"Music therapy is a systematic process of intervention wherein the therapist helps the client to promote health, using music experiences and the relationships that develop through them as dynamic forces of change."

Bruscia [11, p.20]

Typically, music therapists are expected to be technically able musicians with good improvisatory skills. They will use these musical skills, perhaps over a prolonged period of time, to develop a relationship that can be described as being either a client-therapist relationship or a client-music relationship. In the client-therapist relationship music will be used in therapy, and the emphasis will be on the therapist as musician whereas in the client-music relationship, the music will be used as therapy with the emphasis being on the musician as therapist [11].

More an ideology, Community Music places significant emphasis on the individual values that can be gained from taking part in collective music making. Though there may not be specific therapeutic aims within Community Music as such there can, and often will, be therapeutic outcomes that can be observed (e.g. benefits from social inclusion, physical health and mental well-being). As with Music Therapy, the Community Music practitioner is likely to be a good improviser but though high technical skill might be an added strength it is not essential. The Community Music practitioner's real skills lie in being able to quickly respond to the needs and diverse abilities of a possibly unfamiliar group of people whilst constructing ways of making music in the moment.

There are philosophies for free improvisation in music (e.g. $[12,13])$ and in the arts in general (e.g. [14]) that encourage us to embrace the notion of play in music and the applications and benefits of musical play in both Music Therapy and Community Music are quite apparent. In Community Music in particular, considerable emphasis is placed on understanding how best to encourage such play through introducing groups to game-like exercises using all manner of sound sources including those we can make with just our bodies alone. Community Music embraces the idea that anyone can create sound and therefore everyone will have something to offer as music, at its most fundamental level, can be thought of as organised sound. Moser and McKay [15] provide a comprehensive resource for Community Music practitioners along with various approaches to musical game-play $[16,17]$. However, there are clear barriers for individuals with, for example, restricted mobility or perhaps learning difficulties that will impact on the range of instruments and therefore opportunities that might be available. It is here that assistive music-technologies can contribute greatly by enabling such individuals to engage in as expressive a way possible; translating limited movement into larger musical gestures, or mapping complex musical patterns 
onto less complex and more intuitive actions. In this respect, assistive musictechnologies will include adapted and novel acoustic and digital 'instruments' including those that are almost toy-like, where the interaction is as important as the sounds the object can produce. Assistive music-technologies feature within both Music Therapy [18] and Community Music [19] and contrasting technologies were observed in use in the following study though a more comprehensive overview is provided in the section after this.

\section{Sensory spaces in practice}

In an attempt to cast some light on the contrasting perceptions of what a 'sensory space' can be, a short series of case studies has been carried out across a number of special needs schools in England and Wales. As a survey, both the choice of schools to visit and the subsequent interviews with practitioners has been deliberately open and as such there is no suggestion that any of the observations being offered here should form the basis for generalisation. There are some recurring themes but this is a small study and care should be taken not to suggest that these represent the norm and, whilst acknowledging that there may be occasional commonalities, greater emphasis has perhaps been placed on those comments and observations that are unexpected or novel. So, the study should perhaps be thought of as an exploratory journey; an opportunity to appreciate the variety of attitudes, techniques and resources that are currently in use. The findings are being shared here simply as examples of contrasting practice and though individual opinions and choices might inspire some discussion this is not meant to be judgmental or critical in any way. However, out of respect to those who have been helpful enough to share both their time and experience, no references are made to either individuals or the schools where they work.

In total, nine schools have been visited with many of these having a significant proportion of children with PMLD children though two of the schools had a higher proportion of autistic children. Each visit involved an open interview and a tour of any resources and spaces where sensory learning regularly takes place. On most occasions it was possible to see staff and pupils engaged with sensory activities though this was very much dependent on whether an activity happened to be timetabled at that same time. The case studies are not discussed separately, instead they are presented here alongside each other in reference to a number of themes that emerged across the study and though an identifying number is attached to each school this is only for reference purposes such that connections can be made between schools and themes. Although there is an underlying focus on the passive and active uses of sound and music within sensory spaces in the collected observations the approach to questioning was quite open, considering all approaches to working with sensory activities in purpose designed spaces.

\subsection{Perceptions and attitudes}

Of the schools visited, six out of nine were generally positive about the use of sensory rooms within their provision. Within these six, if there were negatives iden- 
tified, these generally related to the practicalities of maintenance and scheduling of activities rather than any underlying philosophical issues. In contrast to this, the key contact at School 8 was keen not to start a tour at the dedicated sensory spaces, instead preferring to focus on aspects of the general environment that had been designed to encourage a wide variety of 'organic' sensory experiences. As an IT coordinator, the interviewee was happy to promote the use of technology and virtual activities but against a backdrop of understanding where and why this might be appropriate. A key example that she offered was the opportunity for a child to interact with an animal (the school has chickens) with meaningful sensory stimulation from stroking, smelling, seeing the bird move, hearing it 'cluck' and so on. Her concern was that in gravitating towards the technological, the environmental can be overlooked and that this is a fundamental aspect of life. In this sense music is sound and any sound can be music. Much of the sensory work at School 8 was based on the Touch Trust ${ }^{2}$ model and music and sound featured heavily within this but not necessarily within dedicated sensory spaces. Interestingly, technology was seen as being an asset within this for the simple reason that many musical instruments are quite simply inaccessible for the children at the school. Here, assistive music-technology was seen as having an appropriate and enabling role to play.

In a similar vein, the member of staff at School 1 was also cautious about a tendency to overly rely on technology and generic sensory equipment expressing a preference for Intensive Interaction. This approach to developing basic communication does not require a sensory space as such and though the school has two sensory trolleys there is no dedicated sensory space. The Intensive Interaction Institute $^{3}$ describes Intensive Interaction as:

"First and foremost, Intensive Interaction is highly practical. The only equipment needed is a sensitive person to be the interaction partner. The approach works by progressively developing enjoyable and relaxed interaction sequences between the interaction partner and the person doing the learning."

Nind and Hewett describe this in practice:

"The practitioner attempts to engage the learner in one-to-one interactive games with the emphasis being on pleasure first and foremost. This involves practitioners in modifying their usual body language, voice and face in order to make themselves attractive and interesting to their less sophisticated partners. A central principles is that the content and the flow of the activity follows the lead of the learner through the practitioners responding to her/his behaviour." Nind and Hewett [20, p.8]

Employing this approach does not exclude additional sensory activities and music and sound are strong features of the daily activities that the children

\footnotetext{
${ }^{2}$ http://www.touchtrust.co.uk

${ }^{3}$ http://www.intensiveinteraction.co.uk
} 
take part in. This same school has a visiting music therapist who also employs Intensive Interaction techniques by mirroring the movements and gestures of the child with complementary melodic and rhythmic phrases.

The other school that did not wholly embrace sensory spaces was School 4 where there was considerable criticism on the generic designs that exist within many SNE schools. The observations by members of staff (including the IT coordinator) at School 4 were that, in general, sensory rooms (gardens, trolleys and so on) are not designed and equipped by educators, more 'specified' by companies that have an interest in selling specialist equipment. This particular school was in the process of moving into a new building and staff had designed the plans for the sensory spaces after much reflection on a number of negative experiences of working with generic designs in a previous building. Two sensory rooms were being designed and, though a commercial company would ultimately install the specialist resources, the school's staff were the driving force behind the equipping of the spaces. This design strategy is elaborated further in the following section and the message was a simple one - the educators and practitioners need to have substantial input into the design of these spaces else the same issues will keep resurfacing due to the generic nature of sensory space design specifications.

One common theme that appeared was that, where a school had a "traditional' sensory room similar to the Snoezelen model, the sensory space was generally regarded as simply being a good place for one-to-one activities. This was frequently reflected in the timetabling structure where individual members of staff would be offered set times within the space which they could then use in whichever way suited their needs.

\subsection{The spaces}

At the time of the visits, all the schools had specialist commercial sensory equipment but only School 1 did not have a dedicated sensory space, instead having two sensory trolleys. Schools 7 and 8 both had light and dark sensory rooms though both the activities and resources being used suggested that these were mainly regarded as general-purpose sensory spaces. The remaining schools all had at least one dedicated sensory space and possibly some additional sensory corners set up within one or more classrooms. Schools 2 and 6 stood out as having considerably more investment in sensory spaces and commercial resources than the other schools. Both were relatively new buildings containing one or more sensory rooms, a sensory corridor, sensory garden and a hydrotherapypool with additional sensory resources. Though the individual types of resources are discussed in the following section, it is worth mentioning that the sensory spaces in these two schools were technology rich yet, in contrast to this, these were not necessarily the spaces that became the most memorable. Again, this is perhaps partly the result of recognising similar technologies in many different places such that when a space is seen that contains none of this same technology it simply stands out; someone has gone to considerable effort to create and equip a space with all the right objects and materials for a very specific group of users. Such a space was seen at School 7 where the backroom to an arts-classroom 
had been converted into a DIY sensory space. More will be made of the kinds of resources that were in this space in a later section but the point of interest here is the notion of generic designs versus small-scale ad-hoc design where the latter immediately seems more in touch with its users. One final observation worth discussing is that most staff mentioned taking additional sensory activities into the dedicated spaces rather than relying on the specialist equipment within. Without undertaking a comprehensive survey on specific usage it would be difficult to determine the individual worth of commonly included technologies but this practice does reinforce the earlier observation on one-to-one activities.

\subsection{Specialist technologies}

As mentioned earlier, the sensory resources in all the schools visited tended to be drawn from roughly the same set: bubble-tubes, fibre-optic lighting, light-wheel, infinity tunnel, interactive switchboard, mirror-ball, audio playback. In talking to staff though, it was not clear why these particular technologies should be included specifically beyond being part of the original fit-out. With Pagliano's observations on the evolution of the Snoezelen in mind and how the emergence of the discotheque was influential within this there is at least some explanation as to why these technologies might be in use but their inclusion also appears both prescriptive and inflexible. The same was true for sensory gardens in that the same technologies tended to be present including interactive switches that trigger sounds, wind-chimes, interactive water-fountains and bubble-machines. The IT coordinator at School 5 gave an account of the original installation of the equipment for the school's sensory garden whilst also pointing out that most of the technology no longer worked. When first installed, there were two artificial plants with switches that when pressed would produce a sound. However these sounds were relatively unconnected (an animal noise for example) but when the system was checked to see how the sounds could be changed (e.g. to make the sound of a bee), it became clear that only one of the company's engineers could really alter the sound set; the sounds have not been changed as a result.

Some of the schools had interactive floor-projectors; perhaps most notably the two schools mentioned earlier that had clearly invested quite substantially in sensory equipment throughout the entire school. The IT specialist at School 7 was using interactive projections but was also not keen on the way in which they tended to be set up. He suggested that there is a tendency to use them in their default or demo settings (disturbing leaves on a surface, revealing parts of pictures etc.) even if this may not be a meaningful interaction for the child taking part. He described how he had set up such a device to track a ball that a child would throw such that a trail could be added visually. In this context, he added, the child is having his or her own actions reinforced in a meaningful way, helping them understand the path of the ball in relation to their own movement and all within quite playful and enjoyable interaction. So he was using technology but tailoring its use to very specific needs and learning outcomes.

Before moving on to talk about repurposed technologies, it is worth reflecting on the observation offered whilst at School 5 that much of the sensory garden 
equipment no longer worked. This was quite a common observation across the different visits with references to equipment failing easily and ultimately being costly to replace and/or maintain. However, there was another factor as to why some equipment was not being used and this related to complexity. Certain technologies are easy to use and work with whilst others require some level of training to allow the activities to move away from the pre-programmed or default settings. The control software for the hydro-pools is a good example of this with consensus from all schools that this particular resource can be incredibly complex to work with. Anecdotally, this same software has also been trialled by two specialist theatre technicians ${ }^{4}$ with similar results. Regardless, this software still regularly forms the basis for control within new installations of this type. On a smaller scale, it is often the case that a school will have one or more Soundbeam systems yet these will not always be in use within sensory activities. There is an element of training required to fully understand how to use these devices and this perhaps leads to them being perceived as highly specialist; it is not uncommon to find one member of staff being identified as either the main or only user of the system. As described earlier, assistive music-technologies can be hugely enabling and expressive devices, allowing children to create and control music and sound in a quite magical way. However, the IT coordinator at School 5 explained that, in her experience, the devices were often allowed to fall into disuse as a result of inexperience.

\subsection{Repurposed technologies}

There have been a number of examples of adapted, found and repurposed technologies in use within some of the spaces visited. The art-classroom sensory space in School 7 was laid out like a fantasy grotto, with Christmas fairy lights adorning the side wall and all manner of tactile materials attached to surfaces and objects. Plastic drinks bottles were hanging in a row from the ceiling to make a percussion instrument and the girl that was in the space at the time was clearly enjoying herself with the various sensory opportunities that were being offered to her. In the same school, the IT coordinator had been experimenting with off-the shelf gaming devices like the Microsoft Kinect to capture movements and map them to sound and images. Drawing partly on the work of Keay-Bright [21] whilst also repurposing software intended for the VJ market, this tutor was clear to point out why he was turning to these types of technologies. Some of the children he works with have difficulty working with the kind of switchtechnology that might normally be used to trigger sound and music, so rather than sidestep those sensory opportunities he had been looking for non-contact approaches to interaction. As with a number of the other schools, he was familiar

\footnotetext{
${ }^{4}$ Two members of specialist technical staff working in a university theatre space were asked to trial and appraise the software in an effort to better understand how complex the system is. Even with professional knowledge of controlling theatre lighting and sound, the system was quickly identified as being unintuitive to both program and operate.
} 
with Soundbeam for music making activities of this type but had found a highly cost-effective and versatile alternative platform in Kinect. He was also exploring the use of smartphones and tablets for similar reasons, not so much because of the touch-sensitive surface but more for the touch-free opportunities that are offered from image tracking using the inbuilt camera. There are now a number of apps that use this technique to provide Theremin and Soundbeam style interaction with music and sound. Indeed, this interest in mobile technologies as tools for mapping actions to sound and music was echoed by practitioners at many of the other schools though all of them acknowledged that given the context in which they are being repurposed, they are generally not robust enough.

In School 5, the IT coordinator explained that of all the technology that the school had within its sensory spaces, the most successful was probably an old disco sound-to-light unit; this was housed within the main sensory room and was known to be a popular activity with many of the children. The reasoning behind this seems to be that the child is much more influential in the final outcomes as it is their own actions that appear to create the light patterns. There is a common picture here as many of the activities that are built into the generic sensory rooms are generally quite passive or involve basic causeand-effect actions (press a switch, hear a sound). The IT coordinator at School 5 was keen to identify this as being an outmoded attitude that perhaps dates back to a period where switch-based access to control/communication was seen as being an essential component of developing basic life-skills. She added that technology had progressed so rapidly that there is now a far richer set of assistive tools available such that approaches to interaction ought to be richer and more flexible yet this often does not seem to be the case.

One of the teachers in School 3 demonstrated a collection of early learning toys and instruments that had been repurposed for use by some of the children with particularly complex needs. Though the school is well equipped with sensory spaces and specialist technologies, the teacher described how some of the toys she is using are perhaps more likely to make a connection as they were simply fun to use. Her emphasis was very much on encouraging interaction through play and she also suggested that the tangible nature of the objects and their natural multisensory nature were all appealing within this. Some of the children in her group have visual impairments in addition to profound learning needs so toys and gadgets that make sound are of great interest, but particularly so if the tactile and haptic stimulus offered is engaging too.

\subsection{Activities (Music and sound)}

The auditory interactions observed (and heard) can broadly be defined as being either passive or active. Passive activities would use music and sound as a listening experience, perhaps to accompany another activity but possibly as a passive activity in its own right; listening to an audio story for example. As an active interaction, the sound or music was being created or influenced at some level by the individual engaging with the object (instrument, toy, gadget). Of interest here is the level of freedom the individual was afforded whilst playing with the 
sound objects. For example, were any choices available or was the interaction perhaps limited to a small and discrete set of outcomes?

For many of the dedicated sensory spaces, music and sound appeared to be either passive or very limited cause-effect style interaction. It was observed that music was often used as a background component to create a relaxing atmosphere rather than offering opportunities for the sound to be either created or controlled. This was understandable in an environment like a hydrotherapy-pool where another activity was being facilitated but was perhaps a little surprising in the dedicated sensory spaces. Even in the dedicated spaces, the emphasis on active interaction seemed to lie predominantly with tactile and visual stimuli rather than auditory; where active interaction was observed it appeared to be in the larger classroom areas. A common theme that emerged across most of the schools was the idea that sensory activities could occur quite easily and fluidly outside of a dedicated-space such that these spaces were only really used where one-on-one interaction was an absolute requirement. The following are a few examples of ways in which staff used music and sound based interaction outside of sensory spaces but within structured sensory activities. It should be added that all schools were exploring sound and music at some level and that staff connected with these activities were keen to point out that PMLD children respond quickly and enthusiastically to sound-focused interaction. It was also suggested that an auditory-stimulus is likely to receive a stronger and more positive response than that from visual-stimulus.

In School 1 (the school without a sensory space), a key member of staff described how music and sound featured throughout the day within a range of sensory activities that also included Intensive Interaction; this was a relatively small class of PMLD children some of whom were described as being pre-speech. Each morning, the group would take part in a musical activity where a beat would be created, perhaps as a rhythm to a piece of music, perhaps as part of a story, or perhaps as part of name-game. The group would use hand-percussion and, where this was too difficult for the child, they could work with a supportteacher to create a sound. The same was true of speaking names in the name game where support-teachers might work with the child to say their name with and/or for them perhaps using technology (e.g. BIGmack ${ }^{\circledR}$ switch) to enable the child to trigger a sound or a recording of their name. The member of staff was keen to point out how meaningful it was for the children to be able to hear and 'say' their name in this way adding that each of the children had a recorded personalised story that could be played to them, often with key sounds that would bring additional meaning to the story. She also reinforced how important rhythm was in the daily activities describing how one particular girl would latch onto the rhythmic footsteps within an audio-story they used quite frequently. The children required little encouragement to make rhythm in this way and so rhythm featured quite heavily where possible.

School 1 was also the same school where Intensive Interaction had been adopted as a means of encouraging and developing communication. Intensive Interaction considers that, in its broadest sense, communication is really derived 
from a set of characteristics that are not wholly reliant upon speech: learning to give brief attention to someone else, sharing attention, learning to concentrate on another person, developing shared attentions into activities, taking turns in changes of behaviour and so on. All against a backdrop of having fun through play. So, an Intensive Interaction session might begin by creating the opportunity by which a child might give brief attention to someone else. Someone might mimic the physical or vocal gestures a child is making such that their attention is drawn by this apparent repetition of their own actions. The child moves, the teacher moves in the same way and a connection is made. An example of this in practice occurred quite organically during the visit where a young girl had picked up a set of handbells and was shaking them quite rhythmically. The support-teacher joined in, copying the rhythm. When the girl swapped the bells to her other hand, the support-teacher did the same and when the girl swapped again, so did the support-teacher; game-play had occurred in a most natural sense and with no need for a set of rules.

This playful mirroring of actions went on for a substantial period of time and the key member of staff explained how the exchange that was happening was quite indicative of the way in which Intensive Interaction could work with sound, adding that the children were generally much more responsive to sound and music than they were to light and visuals. It was because of this that so many of the activities they use incorporate sound and music in some way. She also added that as the children became more responsive to these game-like exchanges they would occasionally respond to each other's rhythmic sound with one of their own. So, communication at a very fundamental yet meaningful level was being achieved with pre-speech children, perhaps simply as an indication of 'I'm here' or establishing that 'I'm part of this'. The Intensive Interaction sessions were complemented by similar sessions with a music therapist who would use musical gestures to mimic and copy the physical gestures or vocalisations of the children.

In School 8, two members of staff were creating sensory spaces within standard classrooms using a variety of technologies and materials. Though the school had dedicated sensory spaces these were seen as being timetabled areas where one-on-one work might happen whereas these sensory spaces were being designed to be group based. The environment would be set in place for perhaps a week or so at a time or until most of the children had been given the opportunity to experience it. The overall experience might be themed (the seaside, the supermarket, the forest etc.) with a multisensory approach being used to create an ambience. The staff were working from the arts-focused Touch Trust model and were using a combination of music-technology (Soundbeam etc.), lighting, projected images, fabrics, textured materials and even smells. Unlike some other uses of audio within sensory experiences there was considerable emphasis on active interaction such that there were opportunities for the children to become part of the music. As with the previous school this might involve using assistive switched-technology (BIGmack ${ }^{\circledR}$ ) to trigger sound but might also involve the child making sound through continuous movement (Soundbeam). 
In a similar way to School 8, staff at School 2 were also creating themed sensory environments outside of dedicated spaces, most notable in a corridor where a similar combination of technologies and materials was in use and, as with School 8, very much aimed at group-based activities. A lightweight framework was used to allow objects and lights to be held in place such that children could move in and around the environment. Similar to School 8, the audio was also being triggered using Soundbeam but here there were a number of these devices in use, each creating one part or layer of an overall musical texture. Though sound could be passive as the children interacted with the other elements of the environment they could happen across a 'beam' and produce a sound. This would change or contribute to the background ambience in some way leading to naturally occurring play with the child hearing the musical interpretation of his or her own actions. Within a context of timetabled activities this was probably quite effective though it was also clear that for those children who were making their way from one location to another it could be quite confusing. Indeed, personal experience has demonstrated that PMLD children with a visual impairment can find this sudden exposure to unexpected sound quite distressing. Ultimately, it was not made particularly clear why the corridor was regarded as being a better place to create a sensory space than a conventional classroom.

School 5 was also using resonance boards in certain activities. These are simple plywood platforms that allow a child to feel vibrations from their own interactions with the surface of the board. Very simple in construction, these are essentially a homemade resource based on an original concept by Lilli Nielson, the Danish psychologist, special education adviser and pioneer in Active Learning. Though the main function is one of transmitting vibrations to a child who is touching or possibly sitting on the board, the vibrations can originate from a sound source such that speaking onto the board or touching noise-making objects onto the surface will work well. Often, the board itself is used as the sound source with children exploring the surface by scratching or tapping to create both noise and vibration.

\section{Technologies for musical play}

There are numerous new and novel technologies that assist with musical improvisation and game-play and these can be placed into three broad categories: mainstream commercial technologies, specialist assistive technologies and researchbased or 'novel' technologies. Mainstream commercial technologies can be thought of as those that are specifically aimed at a reasonably large market of people who wish to make music but have little or no formal training. These range from technologies that are aimed at a domestic market for home entertainment (including smart-phone apps and gaming devices) to a more professional end of the market (DJs, dance music production) where accessible but more musically sophisticated tools are in considerable demand. In the specialist assistive category, there are those musical-tools and instruments that have been designed primarily for use within special needs education and/or therapeutic settings (e.g. Soundbeam, 
MIDI Creator etc.). Whilst in the research/novel category, there are emerging technologies that may offer musical opportunities but are perhaps not widely available. It would be possible to discuss these technologies within the three suggested categories however there are similarities of technology and design that exist across two or more of the categories. With this in mind, some key technologies are presented in the following section grouped by virtue of the types of interactivity on offer.

\subsection{Pressure-sensitive}

There are a range of pressure sensitive digital musical instruments (DMIs) available commercially many of which are designed to take the place of conventional hand percussion (congas, djembes, tablas, chimes etc.). There are obvious benefits of being able to replicate a wide variety of acoustic percussion instruments electronically in this way and easily switching between different and possibly quite cumbersome or heavy items is just one of these. Of the commercially available DMIs that provide pressure sensitive pads, the Korg Wavedrum and Roland Handsonic both stand out as being both accessible and versatile. The Wavedrum provides a single membrane (very much like that on an acoustic snare drum) to strike with fingers, hands or sticks. Designed to sit in a stand or on table or lap, there are sensors under the skin and within the rim that respond in different ways such that a variety of tones and timbres can be achieved. For example, tapping the rim might trigger a complementary sound to the one achieved by hitting the main skin which; the surface also lends itself to being scratched to produce different tones. Other than providing easy, expressive and responsive access to a wide variety of hand percussion sounds, it also provides an array of pitch sounds and looped samples to work with such that a single 'hit' can produce a substantial outcome.

In contrast to the Wavedrum, the Handsonic offers an array of pressure pads (ten or fifteen) arranged on a surface not dissimilar to the size of a conventional snare drum. The ten-pad version in particular is as easy to work with on a lap as it is on a table top or stand and the pads can be easily and effectively controlled with the fingers and/or palm of a single hand if needs be. The individual pads are particularly sensitive such that delicate fine taps can be achieved whilst not having to strike the pads that hard to reach much higher volumes. Other than offering a similar range of percussion sounds to the Wavedrum, the Handsonic also offers a number of pitched percussion patches to work with (xylophone, steel drum etc.). Both versions of the instrument have a Roland D-Beam built in that allows hand gestures to be mapped to sounds or processes (this and similar technologies are discussed in a following section). The larger, fifteen pad, instrument also offers two ribbon strips for similar purpose.

\subsection{Touch-sensitive}

Aimed primarily at the DJ market, the Korg Kaoss Pad was originally presented as an intuitive method of bringing real-time SFX processing to any audio the 
user might care to input (music, speech etc.). Although not functioning as an instrument as such, the processed audio can be captured as loops or single-shot sounds for further playback. In the same way that the BIGmack ${ }^{\circledR}$ can be used to quickly capture sound for playback so can devices like the Kaos Pad making them useful tools for recording key sounds and words to be used in a name-game for example. The SFX processing is controlled using a touch sensitive surface with the $\mathrm{X}$ and $\mathrm{Y}$ dimensions being mapped to different controllable parameters (volume, modulation, effect or filter depth etc.) and the housing is compact and easily held on a lap or table top. The buttons and switches are sensibly laid out with controls for key functions being immediately accessible and particularly intuitive. Much of the functionality of the device is easily accessed from the available controls.

In contrast to the Kaos Pad, the Kaossilator was designed more as an instrument. Interacting with the main pad triggers musical sounds, either individually or according to rules (e.g. arpeggios or rhythm patterns). For example, whilst using a lead instrument setting, the main pad might be mapped as pitch across the $\mathrm{X}$-axis and volume or tone across the $\mathrm{Y}$-axis. For users with limited dexterity, these can be incredibly powerful and expressive sound producing devices.

\subsection{Movement-sensitive}

There are a number of DMIs that respond to non-contact body movement and the inspiration for many of these perhaps comes from the theremin. Developed by Leon Theremin in the early 1920s, the theremin is a touch-free instrument that a performer plays by moving his or her hands near to two antennae; one to control pitch and the other to control volume. The sound is continuous, responsive, highly expressive and quite ethereal in quality. Indeed the unnatural quality of the instrument's musical tones quickly led to its sound becoming synonymous with the cinematic portrayal of alien or future worlds. The instrument is very accessible as there is no requirement for individual finger dexterity and, though the instrument was designed to be used with hands, it can be accessed with any body part that is convenient. This is a feature that Magee [18] comments on, suggesting that regardless of its historic status, the instrument still has a place in mainstream Music Therapy.

There are several music controllers that are theremin like in terms of interaction. Soundbeam is almost certainly the most well known of these and is commonly used in special needs education. Using an ultrasound sensor, an invisible beam is projected across a space and, when interrupted, specific notes, sounds or events will be triggered. The length of the beam and mapping of notes within this are all adjustable such that small movements can be captured (e.g. head motion) as easily as larger whole body movement (e.g. dance). MIDI Gesture operates in a similar way, as does the D-Beam component of many Roland products though this uses infrared technology over a much shorter distance ${ }^{5}$

\footnotetext{
5 The specified distance for sensing movement with the D-Beam sensors is under one
} meter though Brooks [22] has demonstrated how this can be extended greatly to 
than ultrasound can offer easily. Although not commercially available, the Octonic $[23,24]$ is a non-contact DMI that offers eight mini-beams, each of which control a different note or sound such that the player can play notes individually or by gesturing across the whole set. Originally aimed at users with mobility issues, the instrument is designed to be easy to set-up as well as play.

In a similar vein, Beamz uses a series of lasers to create a small light-harp. Breaking a beam triggers a musical phrase that is superimposed on top of a prerecorded piece and phrases are synchronised such that they fit and complement the backing music. Though the player has no direct control over the notes that are produced, the experience of triggering and releasing pre-recorded phrases across a backing is hugely entertaining.

It should also be acknowledged that popular gaming technologies (e.g. Nintendo Wiimote and Microsoft Kinect) are commonly used to create controllers for music and sound in conjunction with music software systems like MAX/MSP from Cycling '74. This is very much in the domain of the DIY and 'hacker' electronic-musician, but the potential for creating accessible systems using such readily available and affordable systems is quite apparent. In a similar vein, it should also be acknowledged that smartphones are also being used for similar purposes, accessing the various embedded sensors to create innovative sound controllers.

\subsection{Switch-access}

Conventional switches as commonly used in special needs education, can be included into some of the systems just described (e.g. Soundbeam and MIDI Creator $^{6}$ ) where they can be used to trigger additional events. However, recent developments in music-making consumerism have led to a widespread appearance of MIDI control surfaces. Primarily aimed at providing access to recording software, such surfaces can be used to send MIDI messages to a computer where they are interpreted into actions. Using appropriate software, it is possible to use such interfaces to trigger recorded loops and samples. This could take the BIGmack ${ }^{\circledR}$ approach to playing back meaningful sounds to another level where a larger set of connected or themed sounds are available. These could be used as part of story-telling or game play in the ways described earlier but with a richer set of opportunities for interaction and exploration.

\section{Reconsidering the design and use of sensory spaces}

The original aim behind this short review of current practice was to consider how sound and music might be used most effectively within sensory spaces but in carrying out the study it quickly became apparent that there is no real consensus of

around 12 meters by using retroreflective microprism; a highly reflective material often found saftey clothing and equipment.

${ }^{6}$ Swingler [25] provides or a comprehensive overview of the Soundbeam system and its applications in special needs education and Abbotson et al [26] provide similar for MIDI-Creator. 
opinion over the effectiveness of such spaces, their usage or their design. In some respects, this might have taken the overall aim slightly off target but there have been key themes emerging along the way that could still influence the design and use of audio-based sensory activities and ultimately the environments in which they might be employed. It seems possible that the original notion of the sensory space is becoming out-dated such that there is no real need to take an individual to a dedicated sensory room. With this in mind, it is understandable that sensory trolleys might become such a familiar feature though the equipment they contain is still quite standardised and with generally only passive applications for sound. Yet outside of this commercial sensory equipment there is evidence to suggest that individual schools and staff members are finding novel means for interacting with sound and music on a needs-led basis. In some respects, it could be a fitting conclusion to reach by suggesting that there is quite simply a need to establish an effective network and repository for sharing observations, concepts, activities and appropriate technologies across as many special needs schools as possible. In the same way that School 4 elected to take a much more involved and prescriptive role in designing their new sensory spaces, it seems only reasonable to suggest that the same should be true for the majority of sensory spaces. After all, who is most likely to have the richer more informed understanding of the therapeutic and developmental needs of the individual than the practitioner who is already working so closely with them? So, acknowledging the effectiveness of ad-hoc, small-scale spaces built around the needs of the individual and gently moving away from the generic commercial resource may well be the way forward but where does music and sound figure within this?

In many of the commercially designed and resourced sensory spaces, music and sound were typically used in a passive sense (as an ambient backdrop to other activities) yet the consensus from the staff being interviewed was that many PMLD children respond more noticeably to sounds in place of visuals. The evidence from observing Intensive Interaction in practice showed that games could emerge quite organically where the 'rules' of the game are established during play. Rhythm, pulse and repetition were cited as having considerable influence in encouraging individual children to engage, as was the importance of meaningful sounds (names, familiar noises etc.). Empowering the individual to move freely and explore seems key within this such that a richer interaction can be achieved where a reliance on quite prescriptive cause and effect activities can perhaps be avoided. Where Intensive Interaction was observed, it was also noted that the visiting Music Therapist adopted these same approaches but by mimicking physical gesture with sound. It could be, though, that given an appropriate and enabling technology these initial gestures could have a sonic output in the first place. Specialist resources were being used in some schools to trigger sounds but these would typically involve a single action (button press) rather than being dynamically responsive (capturing gesture for example). Indeed, some of the exploratory work in one or two of the schools visited suggested that there are intuitive means for encouraging and enabling more dynamic interaction using mainstream technologies including gaming devices, smart phones and touch 
tablets. A quick review of other available music-technologies shows that there are numerous devices that will enable the playback of custom recorded sounds and though these are aimed at a mainstream market they are occasionally very accessible.

There is a real opportunity here to bring together a number of simple concepts to create an engaging environment for musical play within a context of sensory development. Using mainstream music technology (pads to hit, surfaces to explore, gestures to make) can already provide access to a rich variety of sounds. By itself this could be the means for enabling key aspects of basic communication but the evidence would suggest that access to personally meaningful sounds within this set could be even more effective. The early morning musicalgames witnessed at School 1 used recorded sounds that 'belonged' to a specific child, as did the child-specific recorded stories where familiar names and sounds were included. It is not a huge leap beyond this to embed or attach a personalised set of such sounds to a specific device, one that can be chosen to best match the needs or preferences of the individual. Where the magic of gesturing in invisible beams works well for one child it is likely that another will perhaps respond more keenly with a tactile or haptic element. Ultimately, the musical play will exist within the concept of controlling meaningful and personalised sounds and the role of technology can be a simple one; enabling that play to take place. 


\section{Glossary}

Assistive music-technology Where assistive technology refers to technology that is designed to enable a user to engage with activities that might ordinarily be challenging due to individual needs, assistive music-technology refers to those assistive technologies that are focused on music making.

Bubble-tube A common sensory device - essentially a tall cylinder of water with a stream of air bubbles rising from the bottom. Bubble-tubes are often equipped with coloured lighting.

DIY/hacker musician Someone who adapts and reconfigures audio-technologies to create new and unusual sound-generators/instruments.

DJ An abbreviation for Disc Jockey. Originally referring to the person who would select and play the music at a disco, the term has more recently broadened to included elements of music performance where the DJ will mix, adapt and create music within a live environment.

DMI Digital musical instrument.

Haptic Relating to active tactile-interaction of the kind that might exist within a human computer interface.

Infinity tunnel A sensory device that uses a combination of LEDs and mirrors to create an illusion of a never ending tunnel of lights.

Intensive Interaction As defined by the Intensive Interaction Institute: "Intensive interaction is an approach to teaching the pre-speech fundamentals of communication to children and adults who have severe learning difficulties and/or autism and who are still at an early stage of communication development".

Light wheel Originally made for early discotheques, a light wheel uses a rotating disc of coloured lighting gels to project constantly changing patterns onto a suitable surface e.g. a white wall.

MSE Multisensory environment.

PMLD Profound and multiple learning difficulties.

PVC Polyvinyl chloride - a commonly produced type of plastic that is available in both flexible and rigid forms.

Rebound room An area designed to accommodate rebound therapy which typically includes a sunken trampoline surrounded by soft-furnishings.

Repurposed technology A term used to describe technology that is being used in a way that it was not originally designed e.g. a gaming controller being used within an electronic musical instrument. 
Resonance board A flat wooden board that amplifies sounds as someone explores the surface with their hands e.g. scratching, tapping.

Sensory Space A generic term of reference for an area that is designated for sensory activities, also described as a multisensory envirnoment.

SNE Special needs education.

Snoezelen Commercial realisation of the sensory room as originally conceived by Hulsegge and Verheul.

Soundbeam A non-contact approach to triggering and manipulating sound using one or more ultrasound beams. Originally created to enable dancers to produce sound based on their own movements, Soundbeam is an item of assistive music technology that is commonly found in special needs schools in the UK.

Velcro Registered trade name of main manufacturer of hook-and-loop fastener as used for rapid fastening.

VJ An abbreviation for Video Jockey, someone who creatively mixes, adapts and controls video projections in a live performance environment.

\section{References}

1. Hulsegge, J, Verheul, A.: Snoezelen: Another World, Rompa (1988)

2. Pagliano, P.: Using a multisensory environment: A practical guide for teachers, David Fulton Publishers (2001)

3. Pagliano, P.: The multisensory handbook: A guide for children and adults with sensory learning disabilities, Routledge (2012)

4. Bozic, N.: Constructing the room: multi-sensory rooms in educational contexts, European Journal of Special Needs, 12 (1) (1997) pp. 54-70

5. Vlaskamp, K., de Geeter, K. I., Huijsmans, L. M. and Smit, I. H.: Passive activities: The effectiveness of multisensory environments on the level of activity of individuals with profound multiple disabilities. Journal of Applied Research in Intellectual Disabilities, 16 (2003) pp. 135-143

6. Stadele, N. D. and Malaney, L. A.: Effects of a multisensory environment on negative behavior and functional performance on individuals with autism. Journal of Undergraduate Research, IV (2001) pp. 211-218

7. Slevin, E. and McClelland, A.: Multisensory environments: are they therapeutic? A single-subject evaluation of the clinical effectiveness of a multisensory environment Journal of Clinical Nursing, 8 (1999) pp. 48-56

8. Hogg, J., Cavet, J., Lambe, L. and Smeddle, M.: The use of Snoezelen as multisensory stimulation with people with intellectual disabilities: a review of the research, Research in Developmental Disabilities, 22(5) (2001) pp. 353-372

9. Lotan, A and Gold, C.: Meta-analysis of the effectiveness of individual intervention in the controlled multisensory environment for individuals with intellectual disability, Journal of Intellectual and Developmental Disability, 34(3) (2009) pp. 207-215

10. Mount, H. and Cavet, J.: Multisensory environments: an exploration of their potential for young people with profound and multiple learning difficulties, British Journal of Special Education, 22(2) (1995) pp.52-55

11. Bruscia, K. E.: Defining Music Therapy, Barcelona Publishers (1998) 
12. Bailey, D.: Improvisation: Its Nature and Practice in Music, Da Capo Press (1992)

13. Stevens, J.: Search and reflect, Rockschool, UK (1986)

14. Nachmanovitch, S.: Free play: Improvisation in life and art, Penguin Group (1990)

15. Moser, P. and McKay, G.: Community Music: A handbook, Russell House Publishing (2005)

16. Lewis, S.: Drumming, silence and making it up. In: Moser, P. and McKay, G. (Eds.) Community Music: A Handbook, Russell House Publishing (2005)

17. Nankivell, H.: Making new music: Approaches to group composition. In: Moser, P. McKay, G. (Eds). Community Music: A Handbook, Russell House Publishing (2005) pp.79-98

18. Magee, W.: Electronic technologies in clinical music therapy: a survey of practice and attitudes, Technology and Disability, (18) IOS Press (2006) pp.139-46

19. Healey R.: New technologies and music making. In: Moser, P. McKay, G. (Eds.) Community Music: A handbook, Russell House Publishing (2005) pp.161-179

20. Nind, $M$ and Hewett, D.: Access to communication: Developing basic communication with people who have severe learning difficulties (2nd ed.), David Fulton Publishers (2006)

21. Keay-Bright, W.: Designing interaction though sound and movement with children on the autistic spectrum, In: Brooks, A,. L. (Ed.), Arts and Technology, Proceedings of ArtsIT 2011, Lecture Notes of the Institute for Computer Sciences, SocialInformatics and Telecommunications Engineering, 101, Springer (2012)

22. Brooks. A. L. Enhanced gesture capture in virtual interactive space (VIS), Digital Creativity, (16)1 (2005) 43-53

23. Challis, B. P. and Challis, K.: Applications for Proximity Sensors in Music and Sound Performance. In Proceedings of 11th International Conference on Computers Helping People with Special Needs, ICCHP Springer Lecture Notes in Computer Science (5105) (2008) pp. 1220-1227

24. Challis, B.: Octonic: an accessible electronic musical instrument, Digital Creativity, (22)1 (2011) pp. 1-12

25. Swingler, T.: The invisible keyboard in the air: An overview of the educational, therapeutic and creative applications of the EMS Soundbeam, In: Proceedings of 2nd European Conference on Disability, Virtual Reality and Associated Technologies (1998) pp. 253-259

26. Abbotson, M., Abbotson, R., Kirk, P.R., Hunt, A.D., and Cleaton, A.: Computer music in the service of music therapy: The MIDI Grid and MIDI Creator systems, Medical Engineering Physics, 16, May (1994) 253 